Original Research Paper

\title{
Control of Twin Rotor MIMO System using PID and LQR Controller
}

\author{
Seema Chaudhary and Awadhesh Kumar \\ Department of Electrical Engineering, Madan Mohan Malaviya University of Technology Gorakhpur, India
}

\author{
Article history \\ Received: 03-06-2019 \\ Revised: 07-08-2019 \\ Accepted: 08-07-2019 \\ Corresponding Author: \\ Seema Chaudhary \\ Department of Electrical \\ Engineering, Madan Mohan \\ Malaviya University of \\ Technology Gorakhpur, India \\ Email: \\ seemachaudhary875@gmail.com \\ awadhesg26@gmail.com
}

\begin{abstract}
Control design of a TRMS system such as helicopter is very complicated task. Since the TRMS are very high non-linear system, so its non-linearity too high and the control design is very difficult problem for TRMS system. It has two rotors, the first one is the main rotor and the second one is tail rotor. The TRMS System are based on the beam and support by a counter balance. Horizontal and vertical plane are included in the TRMS System for PID and LQR controller both are discuss in this paper. PID and LQR controller both are discuss in this paper. By Simulink result for vertical and horizontal plane, LQR controller better the PID control. All the simulation work is done by the MATLAB/Simulink of the results, environment and the working of simulation results have been done at the end of this paper.
\end{abstract}

Keywords: TRMS System, PID Controller, Linear Quadratic Regulator Controller

\section{Introduction}

The TRMS system is a high order system which is designed by Simulink/MATLAB. It is non-linear system and its non-linearity design of model is very complex. These are the MIMO system which is defined as the Multi- input Multi-output with their significant cross coupling (Allouani et al., 2012). The TRMS system like a helicopter model (TRMS 33-949S). The TRMS system discuss with 2-rotor such that the main and tail rotor. The mail rotor rotated by horizontal plane and tail rotor rotated by vertical plane and angle of rotational is called pitch and tail angle with respectively (Prasad et al., 2013).

TRMS System consists of the two propellers. Both are perpendicular to the each other and it is based on the beam pivoted. The TRMS can be rotated in free of both the plane like that vertical and horizontal direction. The two propellers are run by DC motor as converting the electrical energy into mechanical energy. The changing by the DC motor, voltage supplied to the beam and rotational speed of the propellers can be controlled and for the steady state in balancing. The counterweight is connected to the system. The environmental effects of the two propellers are shielded can be minimized. The complete system model are attached to the tower and which is the ensure safe the helicopter control experiments.

The modelling of the TRMS System is done by using the PID control in (Kannan and Sheenu, 2017).
Bedekar and Shinde (2015), by Robust the Deadbeat Control of TRMS System which helps to improve the transient response and error response. By using deadbeat control method of non-linearity TRMS system applied to the lab-setup, while (Pandey and Laxmi, 2015) TRMS System can be controlled using the optimal control method techniques. The nonlinear system modeling of TRMS system in 1-DOF PID controller is given in (Ahmad et al., 2002) and there are the studies of TRMS system related to the optimal and the robust control can be also found in this studies in (Pratap et al., 2012; Lu and Wen, 2007). The FOPID has the emerged with the fractional calculus based and the fractional order of the operators for the integration and the differentiation parameter such that $(\lambda, \mu)$. The Optimal Controller and suboptimal tracking controller design for TRMS system Using LQR technique base on Integral Action (Phillips and Sahin, 2014). Jagannath et al. (2017), introduction of PID control for the design of pitch and yaw angle of the system which stabilize the main and tail rotor and give better transient response. Carlos et al. (2017), worked on realtime implementation and stabilization scheme and tracking control of pitch and yaw-angle of the system. Vrazevsky et al. (2016), proposed their work on PID control with suboptimal controller LQR for good response of the system to achieve the better steady state response. The auxiliary loop system method applied the robust and suboptimal control algorithms. This is simplified the 
nonlinear system in the form of the linearized model system of the TRMS. Genetic Algorithm scheme gives the result better cost function, I-PD controller can perform real-time implementation. The performance tracking proposed control is satisfy the results and observation of the system up to $25 \%$ considered the reference signals (Ayan and Chakraborty, 2016) and introduces their performance of the model predictive controller with health actuator information in (Jean et al., 2014). The simulation results that satisfy the FOPID controllers more improvement of transient response and error response is better than IOPID controllers and by applying the same method and design criteria (Sunil and Purwar, 2014). It is introduced the PID controller. The use of PID controller for both linear and non-linear system being is done, system stability and trajectory tracking can be detected (Ricardo and Agila, 2015). In this book, to describe the fractional order system with all the robustness and calculus the work (Monje et al., 2010). In this paper, working of the optimal controller with LQR to stabilization of the system and trajectory tracking (Santosh, 2016). Introduces SMC controller and also discuss the state feedback and controller. SMC controller are design to the TRMS system and give the result better transient response of TRMS (Huang, 2011). The design of 1-DOF PID Controller, 2-DOF PID Controller and Fractional order PID Controller for vertical plane and horizontal plane of TRMS System. There are varrious controller used of TRMS System and compare the their results of the controller. By working of controller, the fractional order PID Controller are better response in compare to the 1DOF PID controller and 2-DOF PID controller (Chaudhary and Kumar, 2019).

This paper is organized as fallows: Section 2 mathematical modeling of TRMS System, Section 3 control design strategies, Section 4 describe the step response of TRMS System and result. Finally, conclusions are summarized the all working of varrious type controllers in Section 5.

\section{Mathematical Modeling of TRMS}

The block diagram is shows the components of TRMS System is shown in Fig. 1.

A nonlinear system is the Twin rotor mimo system, their non-linearity are more. They have some simplification to make non-linear to linear system. Thus, we are apply to the linear control theory.

In this Fig. 2, the block diagram shows the TRMS system. The nonlinear equation is derived in the linearized form of TRMS System. The parameters of the system in TRMS are given in the Table 1 and 2. Timeresponse specifications for TRMS system. The nonlinear mathematical modelling of the TRMS system are shown below.

The Mathematical modelling (Chaudhary and Kumar, 2019) of TRMS System for the vertical plane is given by:

$$
\begin{aligned}
& I_{1} \ddot{\psi}=M_{1}-M_{F G}-M_{B \psi}-M_{G} \\
& M_{1}=a_{1} \tau_{1}^{2}+b_{1} \tau_{1} \\
& M_{F G}=M_{g} \sin \psi \\
& M_{B \psi}=B_{1 \psi} \dot{\psi}+B_{2 \psi} \operatorname{sign}(\dot{\psi}) \\
& M_{G}=K_{g y} M_{1} \dot{\psi} \cos (\psi)
\end{aligned}
$$

\section{Where,}

$M_{1}=$ The Parameter of Non-linear static characteristic

$M_{G}=$ The Parameter of Gyroscopic momentum

$M_{F G}=$ The Parameter of Gravity momentum

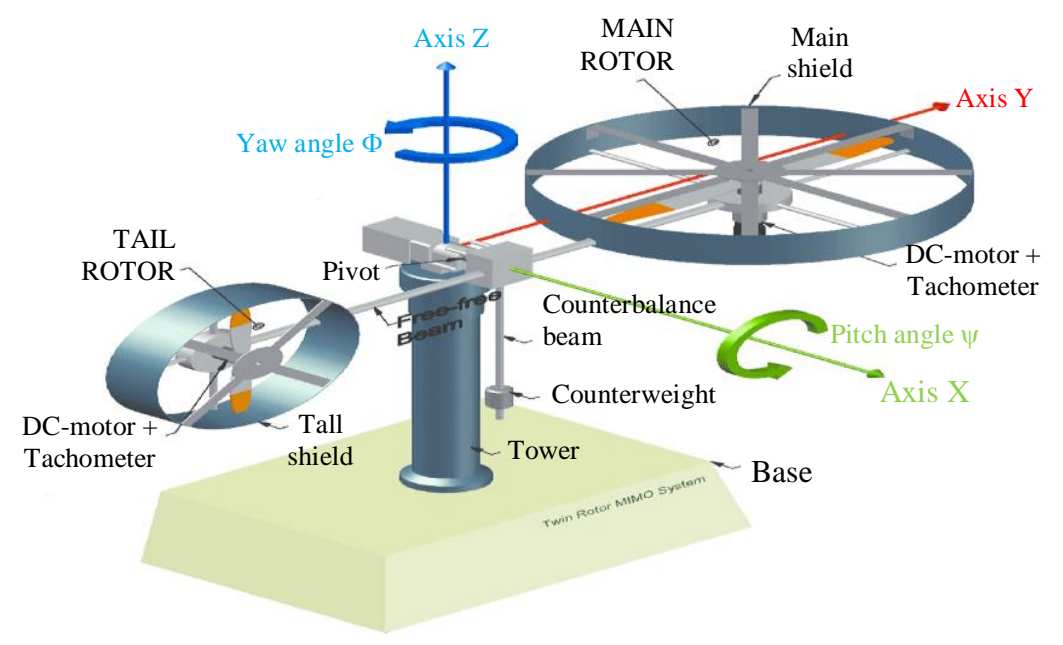

Fig. 1: Block diagram for Twin Rotor MIMO system 


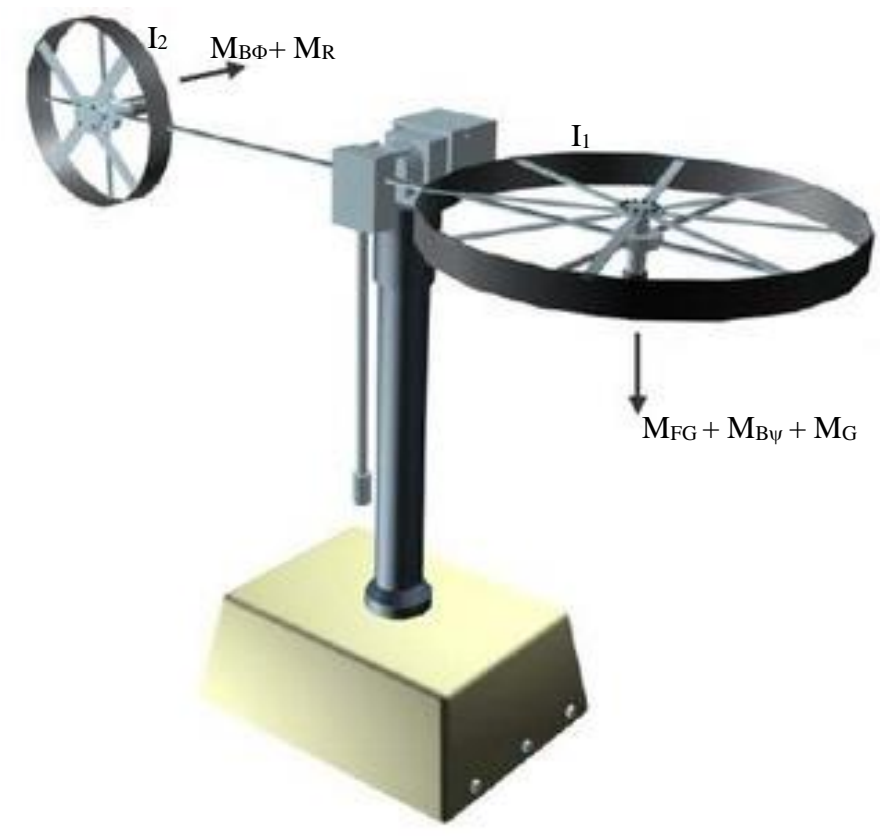

Fig. 2: TRMS for Mechanical-Electrical model rotor:

This Equation (2) shows the momentum of the main

$$
\tau_{1}=\frac{k_{1}}{T_{11} s+T_{10}} u_{1}
$$

Similar, the Mathematical modelling (Chaudhary and Kumar, 2019) of TRMS System for the vertical plane:

$$
\begin{aligned}
& I_{2} \ddot{\phi}=M_{2}-M_{B \phi}-M_{R} \\
& M_{2}=a_{2} \tau_{2}^{2}+b_{2} \tau_{2} \\
& M_{B \phi}=B_{1 \phi} \dot{\phi}+B_{2 \phi} \operatorname{sign}(\dot{\phi}) \\
& M_{R}=\frac{k_{c}\left(T_{0} s+1\right)}{\left(T_{p} s+1\right)} \tau_{1}
\end{aligned}
$$

where, $M_{R}$ is the tail rotor momentum and momentum of response is given:

$$
\tau_{2}=\frac{k_{2}}{T_{21} s+T_{20}} u_{2}
$$

The Table 1 givens the estimated values of a parameters.

\section{State-Space Representation}

The state of the linear plant is given by the statespace modelling (Chaudhary and Kumar, 2019) using dynamic equation:

$$
\begin{aligned}
& \dot{x}=A x+B u \\
& y=C x+D u
\end{aligned}
$$

The State Vector $(x)=\left[\Psi \dot{\Psi} \Phi \dot{\Phi} M_{R} \tau_{1} \tau_{2}\right]^{T}$

The input Vector $(u)=\left[u_{1} u_{2}\right]^{T}$

The output vector $(y)=\left[\begin{array}{ll}\psi & \Phi\end{array}\right]^{T}$

$$
A=\left[\begin{array}{ccccccc}
0 & 1 & 0 & 0 & 0 & 0 & 0 \\
\frac{-M_{g}}{I_{1}} & \frac{-B_{1 \Psi}}{I_{1}} & 0 & 0 & 0 & \frac{b_{1}}{I_{1}} & 0 \\
0 & 0 & 0 & 1 & 0 & 0 & 0 \\
0 & 0 & 0 & \frac{-B_{1 \Phi}}{I_{2}} & \frac{-1}{I_{2}} & 0 & \frac{b_{2}}{I_{2}} \\
0 & 0 & 0 & 0 & \frac{-1}{T_{p}} & \frac{k_{c}}{T_{p}}\left(\frac{-T_{10}}{T_{11}} T_{0}+1\right) & 0 \\
0 & 0 & 0 & 0 & 0 & \frac{-T_{10}}{T_{11}} & 0 \\
0 & 0 & 0 & 0 & 0 & 0 & \frac{-T_{20}}{T_{11}}
\end{array}\right]
$$

$$
B=\left[\begin{array}{cc}
0 & 0 \\
0 & 0 \\
0 & 0 \\
0 & 0 \\
\frac{k_{1} k_{c} T_{0}}{T_{11} T_{p}} & 0 \\
\frac{k_{1}}{T_{11}} & 0 \\
0 & \frac{k_{2}}{T_{21}}
\end{array}\right]
$$


Table 1: Parameters of a trms and unit (Chaudhary and Kumar, 2019)

\begin{tabular}{ll}
\hline Parameter & Value \\
\hline Moment of inertia of vertical plane $\left(\mathrm{I}_{1}\right)$ & $6.8 * 10^{-2}\left(\mathrm{~kg} \cdot \mathrm{m}^{2}\right)$ \\
Moment of inertia of horizontal plane $\left(\mathrm{I}_{2}\right)$ & $2 * 10^{-2}\left(\mathrm{~kg} \cdot \mathrm{m}^{2}\right)$ \\
Static characteristic of parameter $\left(\mathrm{a}_{1}\right)$ & 0.0135 \\
Static characteristic of parameter $\left(\mathrm{b}_{1}\right)$ & 0.0924 \\
Static characteristic of parameter $\left(\mathrm{a}_{2}\right)$ & 0.02 \\
Static characteristic of parameter $\left(\mathrm{b}_{2}\right)$ & 0.09 \\
Gravity momentum $\left(\mathrm{M}_{\mathrm{g}}\right)$ & $0.32(\mathrm{~N} . \mathrm{m})$ \\
Friction momentum $\left(B_{1 \alpha_{v}}\right)$ & $6^{*} 10^{-3}(\mathrm{~N} \cdot \mathrm{m} . \mathrm{s} / \mathrm{rad})$ \\
Friction momentum $\left(B_{2 \alpha_{v}}\right)$ & $1 * 10^{-3}\left(\mathrm{~N} \cdot \mathrm{m} . \mathrm{s}^{2} / \mathrm{rad}\right)$ \\
Friction momentum $\left(B_{1 \alpha_{h}}\right)$ & $1 * 10^{-1}(\mathrm{~N} \cdot \mathrm{m} . \mathrm{s} / \mathrm{rad})$ \\
Friction momentum $\left(B_{2 \alpha_{h}}\right)$ & $1 * 10^{-2}\left(\mathrm{~N} \cdot \mathrm{m} . \mathrm{s}^{2} / \mathrm{rad}\right)$ \\
Gyroscopic momentum of parameter $\left(\mathrm{K}_{\mathrm{gy}}\right)$ & $0.05(\mathrm{~s} / \mathrm{rad})$ \\
Gain of main rotor $\left(\mathrm{K}_{1}\right)$ & 1.1 \\
Gain of tail rotor $\left(\mathrm{K}_{2}\right)$ & 0.8 \\
Main rotor denominator $\left(\mathrm{T}_{11}\right)$ & 1.1 \\
Main rotor denominator $\left(\mathrm{T}_{10}\right)$ & 1 \\
Tail rotor denominator $\left(\mathrm{T}_{21}\right)$ & 1 \\
Tail rotor denominator $\left(\mathrm{T}_{20}\right)$ & 1 \\
Cross reaction momentum of the parameter $\left(\mathrm{T}_{\mathrm{p}}\right)$ & 2 \\
Cross reaction momentum of the parameter $\left(\mathrm{T}_{0}\right)$ & 3.5 \\
Cross reaction momentum gain $\left(\mathrm{K}_{\mathrm{c}}\right)$ & -0.2 \\
\hline
\end{tabular}

Table 2: Time-response specifications for Twin Rotor MIMO system

\begin{tabular}{lccll}
\hline Specifications & $\mathrm{PID}_{\mathrm{v}}$ & $\mathrm{PIDh}_{\mathrm{h}}$ & $\mathrm{LQR}_{\mathrm{v}}$ & $\mathrm{LQR}_{\mathrm{h}}$ \\
\hline Rise Time & $0.244 \mathrm{sec}$ & $0.451 \mathrm{sec}$ & $2.1 \mathrm{sec}$ & $2.97 \mathrm{sec}$ \\
Settling time & $18.300 \mathrm{sec}$ & $4.670 \mathrm{sec}$ & $4.13 \mathrm{sec}$ & $4.50 \mathrm{sec}$ \\
Maximum overshoot & $64.9000 \%$ & $47.800 \%$ & $0 \%$ & $0 \%$ \\
$\mathrm{~K}_{\mathrm{P}}$ & 7.46320 & 7.65990 & - & - \\
$\mathrm{K}_{\mathrm{I}}$ & 34.31790 & 3.46150 & - & - \\
$\mathrm{K}_{\mathrm{D}}$ & 15.28510 & 2.84470 & - & - \\
\hline
\end{tabular}

$$
\begin{aligned}
C & =\left[\begin{array}{lllllll}
1 & 0 & 0 & 0 & 0 & 0 & 0 \\
0 & 0 & 1 & 0 & 0 & 0 & 0
\end{array}\right] \\
D & =\left[\begin{array}{ll}
0 & 0 \\
0 & 0
\end{array}\right]
\end{aligned}
$$

Matrix A, B, C and D calculated by parameters of a TRMS system given in the Table 1 and above Equation (1-8).

System Matrix is given by:

$$
A=\left[\begin{array}{ccccccc}
0 & 1 & 0 & 0 & 0 & 0 & 0 \\
-4.7059 & -0.088 & 0 & 0 & 0 & 1.359 & 0 \\
0 & 0 & 0 & 1 & 0 & 0 & 0 \\
0 & 0 & 0 & -5 & -50 & 0 & 4.5 \\
0 & 0 & 0 & 0 & -0.5 & 0.22 & 0 \\
0 & 0 & 0 & 0 & 0 & -0.909 & 0 \\
0 & 0 & 0 & 0 & 0 & 0 & -1
\end{array}\right]
$$

Input matrix is given by:

$$
B=\left[\begin{array}{cc}
0 & 0 \\
0 & 0 \\
0 & 0 \\
0 & 0 \\
-0.35 & 0 \\
1 & 0 \\
0 & 0.8
\end{array}\right]
$$

Output matrix is given by:

$$
C=\left[\begin{array}{lllllll}
1 & 0 & 0 & 0 & 0 & 0 & 0 \\
0 & 0 & 1 & 0 & 0 & 0 & 0
\end{array}\right]
$$

\section{Transfer Function for TRMS System}

Converting state-space modeling to transfer function by Simulink/MATLAB commands. In this way, we can say that the representation of two the transfer functions i.e., the vertical and horizontal plane. 
Transfer function of TRMS for Vertical plane:

$$
G_{V}=\frac{1.359}{s^{3}+0.997 s^{2}+4.786 s+4.278}
$$

Transfer function of TRMS for Horizontal plane:

$$
G_{H}=\frac{3.6}{s^{3}+6 s^{2}+5 s}
$$

\section{Control Design for TRMS System}

\section{PID Controller Design}

The PID control design is shown in the Fig. 3. The control design can be implemented by controlling the three parameters of the PID controllers: proportional gain $\left(K_{p}\right)$, differential gain $\left(K_{D}\right)$ and integral gain $\left(K_{\mathrm{I}}\right)$. The PID controller of the equations can be written by (11):

$$
e_{a}(t)=K_{P} e(t)+K_{I} \int e(t) d t+K_{D} \frac{d}{d t} e(t)
$$

The designed to stabilize the vertical and horizontal plane of TRMS system for the PID controller.

\section{LQR Controller Design}

The Linear quadratic regulator (LQR) are basically calculate the state feedback control gain matrix.

Let us assume that the system equation (Pandey and Laxmi, 2015) are define in Equation (12):

$$
\dot{x}(t)=A x(t)+B u(t)
$$

Now, calculation of the matrix $K$ is called the optimal control vector:

$u(t)=-K x(t)$

Let us assume that, the minimize the performance index (PI) is given in equation (14)

$$
J=\int_{0}^{\infty}\left(x^{T}(t) Q(t) x(t)+u^{T}(t) R(t) u(t)\right) d t
$$

Where,

$Q=$ Positive-semi definite matrix or Positive-definite matrix.

$R=$ Positive-definite matrix.

The Equation (14) is defined as control signal of the cost of the energy and which is determine by the matrices $Q$ and $R$. Where, the control vector $u(t)$ is assumed to be unconstrained in this problem.

So if unknown gain matrix $K$ of the elements is determined then minimize the $P I$. So $u(t)=-K(t) x(t)$ where, $x(0)=$ initial state The block diagram of the optimal configuration has been shown in Fig. 4.

The optimization problem can be solved by putting Equation (13) into (12), we get:

$$
\begin{aligned}
& \dot{x}(t)=A x(t)-B K(t) x(t) \\
& =(A-B K(t)) x(t)
\end{aligned}
$$

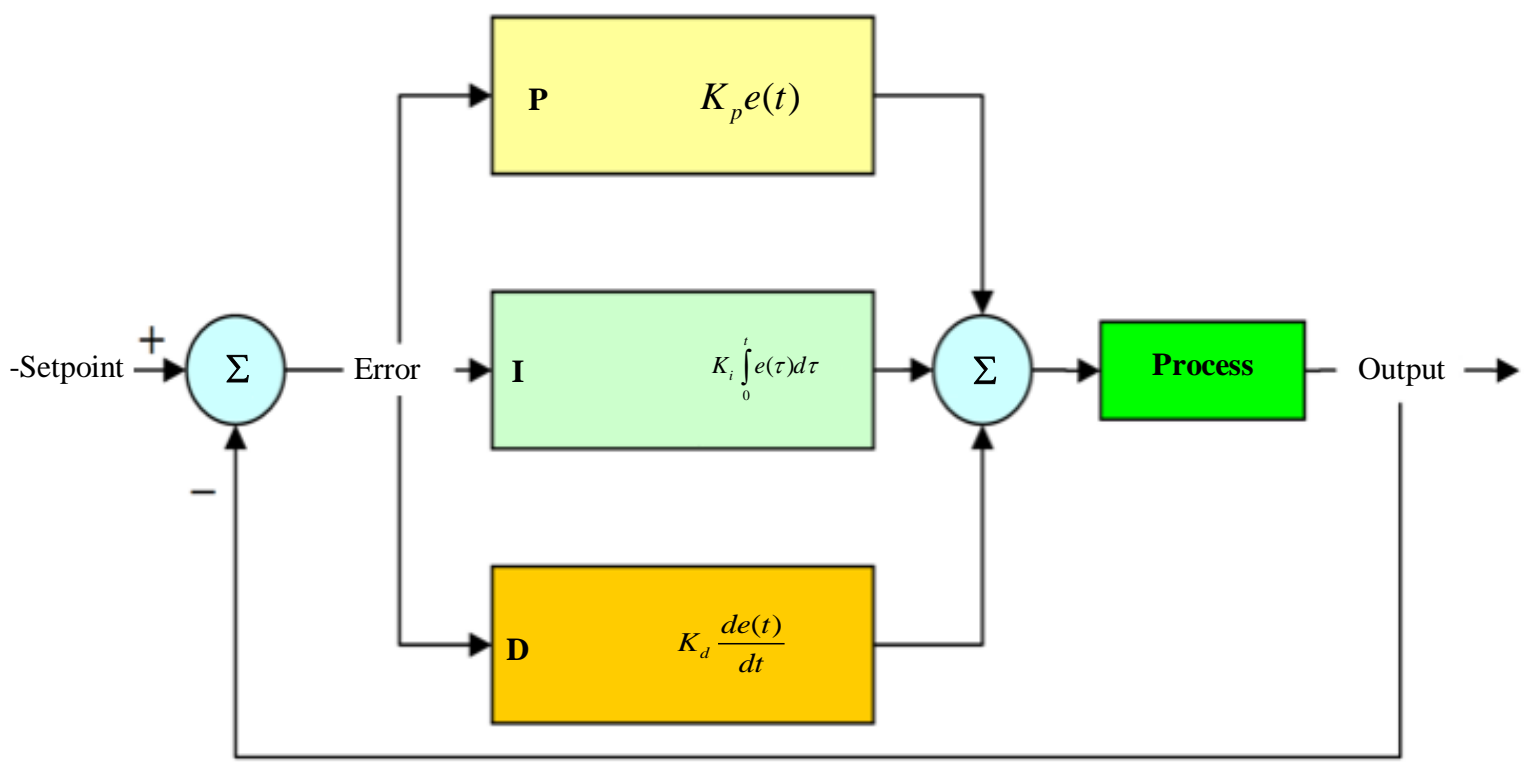

Fig. 3: Block diagram for PID controller 


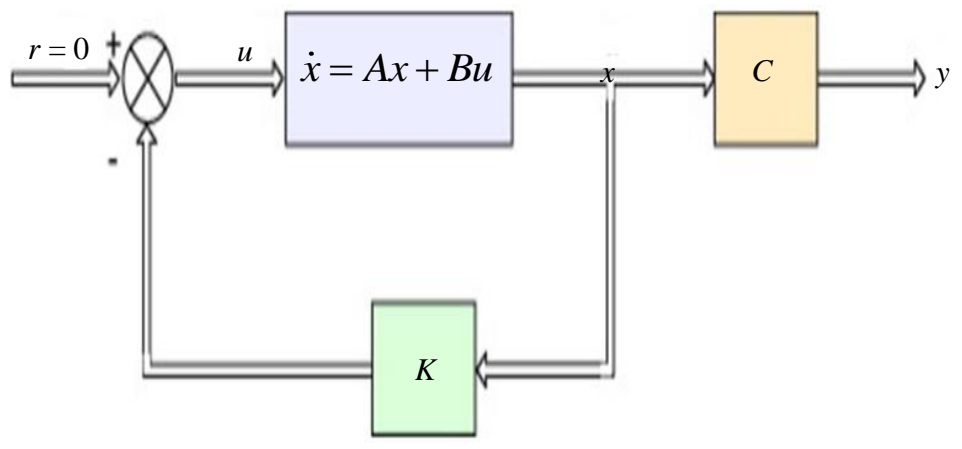

Fig. 4: Block diagram showing optimal configuration

This is assume that Equation (14) i.e., the matrix (A$\mathrm{BK}(\mathrm{t}))$ is stable and the eigenvalues of $(\mathrm{A}-\mathrm{BK}(\mathrm{t}))$ negative real i.e. $(\mathrm{A}-\mathrm{BK}(\mathrm{t}))$ are a negative real parts. Putting Equation (13) into (14) we obtain:

$$
\begin{aligned}
& J=\int_{0}^{\infty}\left(x^{T}(t) Q(t) x(t)+x^{T}(t) K^{T}(t) R(t) K(t) x(t)\right) d t \\
& =\int_{0}^{\infty} x^{T}(t)\left(Q(t)+K^{T}(t) R(t) K(t)\right) x(t) d t
\end{aligned}
$$

Now, consider:

$$
x^{T}(t)\left(Q(t)+K^{T}(t) R(t) K(t)\right) x(t)=\frac{d}{d t}\left(x^{T}(t) P(t) x(t)\right)
$$

where, $P=$ Positive-definite matrix. Then we get:

$$
\begin{aligned}
& =x^{T}(t)\left(Q(t)+K^{T}(t) R(t) K(t)\right) x(t) \\
& =-\dot{x}^{T}(t) P(t) x(t)-x^{T}(t) P(t) \dot{x}(t) \\
& =-x^{T}(t)\left[(A-B K(t))^{T} P(t)+(A-B K(t))\right] x(t)
\end{aligned}
$$

Comparing both side of the above equations of the equations must be true for $x$. Than we consider as:

$$
\begin{aligned}
& =(A-B K(t))^{T} P(t)+P(t)(A-B K(t)) \\
& =-\left(Q(t)+K^{T}(t) R(t) K(t)\right)
\end{aligned}
$$

In Equation (16), where $\mathrm{A}$ is a stable matrix and the positive-definite matrix $P$ that satisfy by the Equation (16). Now, we consider as the elements of the matrix $P$ by Equation (16) and determine its positive definiteness. $\mathrm{P}$ may be more than one matrix i.e., satisfy the Equation (16). So, if the system is stable than positive-definite matrix only one satisfy by this equation.

The performance index $\mathrm{J}$ discusses by the equation as:

$$
\begin{aligned}
& J=\int_{0}^{\infty} x^{T}(t)\left(Q(t)+K^{T}(t) R(t) K(t)\right) x(t) d t \\
& =-\left.x^{T}(t) P(t) x(t)\right|_{0} ^{\infty} \\
& =-x^{T}(\infty) P x(\infty)+x^{T}(0) P x(0)
\end{aligned}
$$

Since, A negative real value is assumed to be (ABK). we have:

$$
x(\infty) \rightarrow 0
$$

Therefore obtained:

$$
J=x^{T}(0) P x(0)
$$

Therefore the PI can be determined as the starting position $x(0)$ and $P$.

To solve quadratic control, the following is the procedure: $\mathrm{R}$ consider as real symmetric matrix or positive-definite Hermitian, in this way we can write as:

$$
R=T^{T} T
$$

where, $T=$ Non-singular matrix. So Equation (16) can be written as:

$$
\begin{aligned}
& \left(A^{T}-K^{T}(t) B^{T}\right) P(t)+P(t)(A-B K(t)) \\
& +Q(t)+K^{T}(t) T^{T} T K(t)=0 A^{T} P+P A \\
& +\left[T K(t)-\left(T^{T}\right)^{-1} B^{T}(t) P\right]\left[T K(t)-\left(T^{T}\right)^{-1} B^{T}(t) P\right] \\
& -P B(t) R^{-1} B^{T}(t) P+Q(t)=0
\end{aligned}
$$

$J$ performance index is with respect to minimize of the minimum of $\mathrm{K}$ :

$$
x^{T}(t)\left[T K(t)-\left(T^{T}\right)^{-1} B^{T}(t) P\right]\left[T K(t)-\left(T^{T}\right)^{-1} B^{T}(t) P\right] x(t)
$$

Since, non-negative equation and this is the minimum when it is zero or when:

$$
T K(t)=\left(T^{T}\right)^{-1} B^{T}(t) P
$$

Therefore:

$$
K(t)=T^{-1}\left(T^{T}\right)^{-1} B^{T}(t) P=R^{-1}(t) B^{T}(t) P
$$

The equation (18) is give the optimal matrix (K). So, the quadratic optimal control of optimal control law 
problem when the PI is discusses by equation (14) is linear and it is given as:

$u(t)=-K x(t)=R^{-1} B^{T} P x(t)$

The matrix $P$ in Equation (18) must satisfy equation (16) or the following reduce equation:

$A^{T}(t) P(t)+P(t) A(t)-P(t) B(t)$

$R^{-1}(t) B^{T}(t) P(t)+Q(t)=0$

Equation (20) known as Algebraic Matrix Riccati (ARE) equation.

Here the obtained value of $(K)$ gain by applying a Simulink/MATLAB command:

$$
K=\operatorname{lq}(A, B, Q, R)
$$

where, the $Q$ has taken as identity matrix for both vertical and horizontal plane while $R=0.1$ for vertical and $R=0.01$ for horizontal plane.

The value of gain for vertical plane is:

$$
K=\left[\begin{array}{lll}
3.25913 .5602 & 1.0419
\end{array}\right]
$$

The value of gain for horizontal plane:

$$
\mathrm{K}=\left[\begin{array}{lll}
6.8487 & 14.5441 & 10.0000
\end{array}\right]
$$

\section{Results of TRMS and Simulation}

See the following magnitude: Simulations of TRMS system in results shows (Step response) in Fig. 5 to 8. Can be improved by using two controllers in MATLAB/Simulink of the time and steady state response in results. The two controllers are PID and LQR controller.

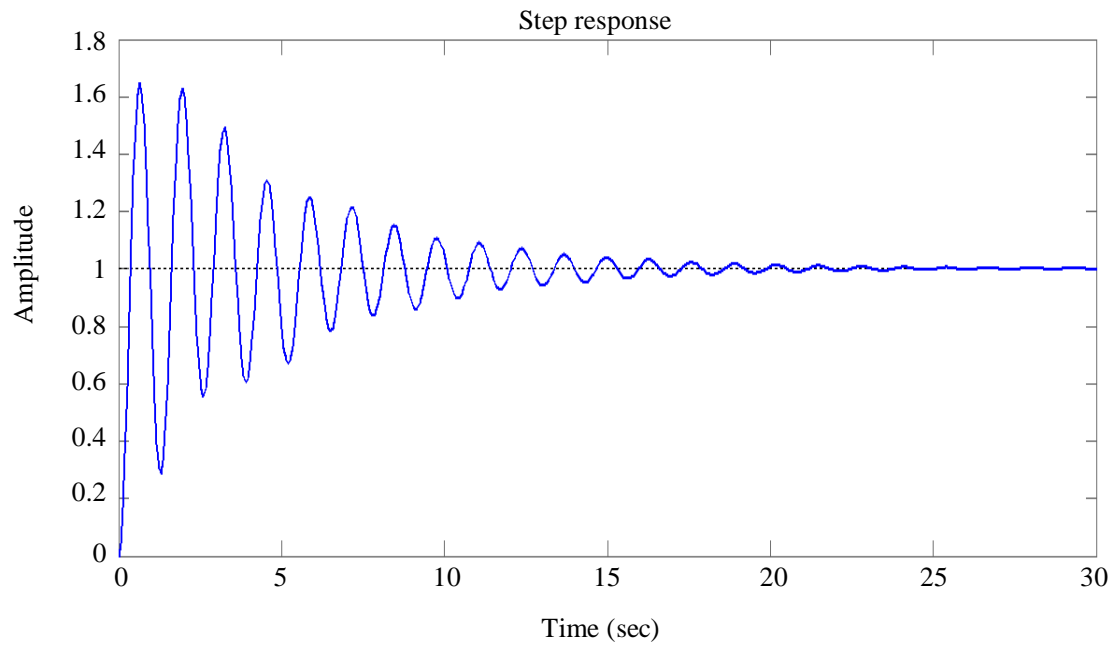

Fig. 5: Step response for vertical plane with PID controller

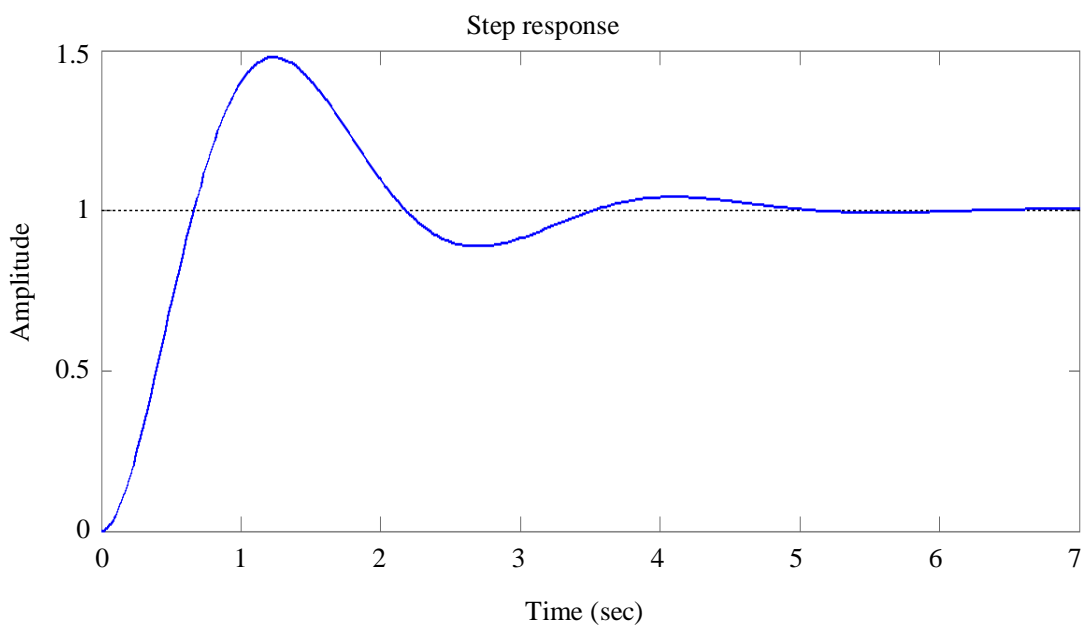

Fig. 6: Step response for horizontal plane with PID Controller 


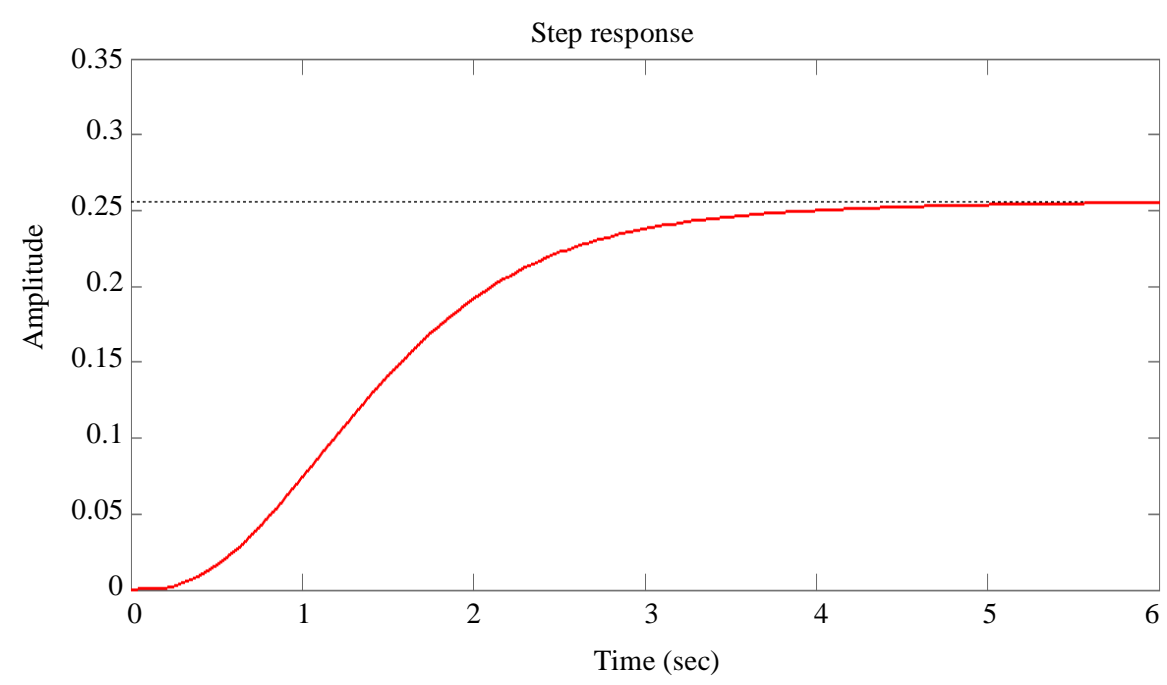

Fig. 7: Step response for vertical plane with LQR controller

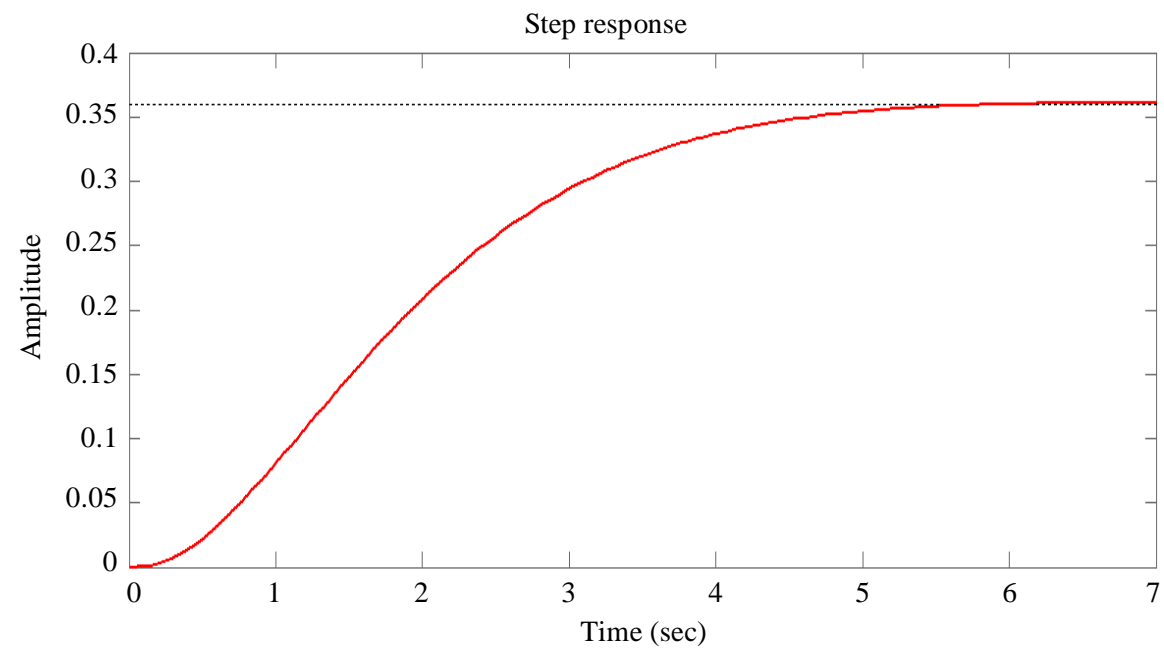

Fig. 8: Step response for horizontal plane with LQR controller

\section{Conclusion}

In this paper work, different type of controllers have been implemented and the give the result to improvement in the steady-state and time response of the system. The design of control is control the TRMS system. There are two controller used such that PID and LQR controllers. The working of LQR controller is more accurate response as comparison to the PID controller, for the error response and transient response. So, LQR controller is good response for the TRMS System. In Simulink/MATLAB, we have better modeling of TRMS system. The LQR controller is applied to the horizontal and vertical plane. But the modeling of TRMS based, we require accurate system transfer function of the system.

\section{Acknowledgement}

The author appreciatively acknowledges the contribution of his supervisor who is the faculty of Electrical Engineering Department, Madan Mohan Malaviya University of Technology, Gorakhpur and friends who have helped in accomplishing the work within the stipulated time.

\section{Author's Contributions}

Seema Chaudhary: Designed the research plan and organized the study. He implemented this work. He contributed to part of the literature collection and drafted. 
Awadhesh Kumar: He devised the main conceptual ideas and supervised this work. He contributed to figure out the whole work as a research paper. Also provided critical feedback and helped to outline the exploration and manuscript.

\section{Ethics}

This paper is an original research paper. This paper is not a ethical issue which is a problem after publication.

\section{References}

Allouani, F., D. Boukhetala and F. Boudjema, 2012. Particle swarm optimization based fuzzy sliding mode controller for the twin rotor MIMO system. Proceedings of the 16th IEEE Electro Technical Conference, Mediterranean, Mar. 25-28, IEEE Xplore Press, Yasmine, Hammamet, Tunisia, pp: 1063-1066.

DOI: 10.1109/MELCON.2012.6196611

Ahmad, S.M., M.H. Shaheed, A.J., Chipperfield and M.O. Tokhi, 2002. Nonlinear modelling of a onedegree-freedom of twin rotor multi-input multioutput system using radial basis function networks. Proc. Instn. Mech. Eng. G., 216: 197-208.

DOI: 10.1243/09544100260369731

Ayan, S. and S. Chakraborty, 2016. Genetic algorithm based I-PD controller design for Twin Rotor MIMO system. Proceedings of the International Conference on Control, Instrumentation, Energy and Communication, Jan. 28-30, IEEE Xplore Press, Kolkata, India, pp: 23-63.

DOI: 10.1109/CIEC.2016.7513826

Bedekar, A.J. and S. Shinde, 2015. Robust deadbeat control of twin rotor multi input multi output system. IJERT.

Carlos, A., M. Bernal, F. Hernandez and R.V. Segura 2017. Identification-based linear control of a twin rotor MIMO system via dynamical neural networks. Proceedings of the 14th International Conference on Electrical Engineering, Computing Science and Automatic Control, Oct. 20-22, IEEE Xplore Press, Mexico.

DOI: 10.1109/ICEEE.2017.8108829

Chaudhary, S. and A. Kumar, 2019. Control of twin rotor MIMO system using 1-degree-of-freedom PID, 2-degree-of-freedom PID and fractional order PID controller. Proceedings of the 3rd International conference on Electronics, Communication and Aerospace Technology, Jun. 12-14, IEEE Xplore Press, Coimbatore, India. DOI: 10.1109/ICECA.2019.8821923
Huang, L., 2011. An approach for robust control of a twin-rotor multiple input multiple output system. Proceedings of the IEEE International Conference on Robotics and Automation, May 9-13, IEEE Xplore Press, Shanghai, China, pp: 13-26. DOI: 10.1109/ICRA.2011.5979536

Jagannath, W., Y. Liyanage, S. Welikala and L. Samaranayake, 2017. Yaw and pitch control of a twin rotor MIMO system. Proceedings of the IEEE International Conference on Industrial and Information Systems Industrial and Information System, (IIS' 17).

Jean, S.C., F. Nejjari and R. Sarrate, 2014. Reliable control of a twin rotor mimo system using actuator health monitoring. Proceedings of the Mediterranean Conference on Control and Automation, Jun. 16-19, IEEE Xplore Press, Palermo, Italy, pp: 89-98.

DOI: 10.1109/MED.2014.6961419

Kannan, P.S. and P. Sheenu, 2017. PID control of twin rotor MIMO system. IJARBEST.

Lu, T.W. and P. Wen, 2007. Time optimal and robust control of twin rotor system. Proceedings of the IEEE, International Conference on Control and Automation, May 1-3, IEEE Xplore Press, Guangzhou, China.

DOI: 10.1109/ICCA.2007.4376479

Monje, C.A., Y. Chen, B.M. Vinagre and D. Xue, 2010. Fractional-order systems and controls: Fundamentals and applications. Springer Sci. Bus. Media.

Pandey, S.K. and V. Laxmi, 2015. Optimal Control of Twin Rotor MIMO System Using LQR Technique. Computational Intelligence in Data Mining. 1st Edn., Springer, New Delhi,

Phillips, A. and F. Sahin, 2014. Optimal control of a twin rotor MIMO System Using LQR with Integral Action. Proceedings of the world Automation Congress, Aug. 3-7, IEEE Xplore Press, Mexico. pp: 1-6. DOI: 10.1109/WAC.2014.6935709

Prasad, D.G., P.S. Manoharan and A.P.S Ramalakshmi, 2013. PID control scheme for twin rotor MIMO system using a real valued genetic algorithm with a predetermined search rang. Proceedings of 2013 International Conference on Power, Energy and Control, Feb. 6-8, pp: 443-448. DOI: 10.1109/ICPEC.2013.6527697

Pratap, B., A. Agrawal and S. Purwar, 2012. Optimal control of twin Rotor MIMO system using output feedback. Proceedings of the 2nd International Conference on Control and Embedded System Power, Dec. 17-19, IEEE Xplore Press, Allahabad, India. DOI: 10.1109/ICPCES.2012.6508113 
Ricardo, C. and W. Agila, 2015. Evaluation of algorithms for linear and nonlinear PID control for Twin Rotor MIMO System. Proceedings of the Asia-Pacific Conference on Computer Aided System Engineering, July. 14-16, IEEE Xplore Press, Quito, Ecuador, pp: 33-69.

DOI: 10.1109/APCASE.2015.45

Santosh, K. C., 2016. Optimal feedback control of twin rotor MIMO system with a prescribed degree of stability. Int. J. Intel. Unmanned Syst., 4: 226-238. DOI: 10.1108/IJIUS-07-2016-0005

Sunil, K.M. and S. Purwar, 2014. To design Optimally Tuned FOPID Controller for Twin Rotor MIMO System. Proceedings of the Students Conference on Engineering and Systems, May. 28-30, Allahabad, India, IEEE Xplore Press, Mexico, pp: 56-69.

DOI: 10.1109/SCES.2014.6880118
TRMS 33-949S User Manual. Feedback Instruments Ltd. East Sussex, U.K.

Vrazevsky, S.A., J.V. Chugina, I.B. Furtat and A.S. Kremlev, 2016. Robust suboptimal output control for a twin rotor MIMO system. Proceedings of the International Congress on Ultra Modern Telecommunications and Control Systems and Workshops, Oct.18-20, IEEE Xplore Press, Lisbon, Portugal, pp: 63-65.

DOI: 10.1109/ICUMT.2016.7765227 